\title{
Object kinetic Monte Carlo study of the effect of grain boundaries in martensitic $\mathrm{Fe}-\mathrm{Cr}-\mathrm{C}$ alloys: Effect of grain boundaries in...
}

Article in Physica Status Solidi (A) Applications and Materials · August 2016

DOI: 10.1002/pssa.201600294

CITATION

1

4 authors:

\section{Chiapetto}

Belgian Nuclear Research Centre

10 PUBLICATIONS 25 CITATIONS

SEE PROFILE

\section{Athina Puype}

Ghent University

2 PUBLICATIONS 7 CITATIONS

SEE PROFILE
READS

63

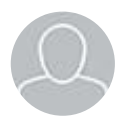

Lorenzo Malerba

Belgian Nuclear Research Centre

156 PUBLICATIONS 2,962 CITATIONS

SEE PROFILE

\section{Charlotte S Becquart}

National Graduate School of Engineering Ch...

141 PUBLICATIONS 3,111 CITATIONS

SEE PROFILE

Some of the authors of this publication are also working on these related projects: 


\title{
Object kinetic Monte Carlo study of the effect of grain boundaries in martensitic $\mathrm{Fe}-\mathrm{Cr}-\mathrm{C}$ alloys
}

\author{
Monica Chiapetto ${ }^{*, 1,2}$, Lorenzo Malerba ${ }^{* *, 1}$, Athina Puype ${ }^{1,3}$, and Charlotte S. Becquart ${ }^{2}$ \\ ${ }^{1} \mathrm{SCK} \cdot \mathrm{CEN}$, Nuclear Materials Science Institute, Boeretang 200, B-2400 Mol, Belgium \\ ${ }^{2}$ Unité Matériaux Et Transformations (UMET), UMR 8207, Université de Lille 1, ENSCL, F-59600 Villeneuve d'Ascq Cedex, France \\ ${ }^{3}$ Department of Materials Science and Engineering, Ghent University, Technologiepark 903, B-9052 Zwijnaarde
}

Received ZZZ, revised ZZZ, accepted ZZZ

Published online ZZZ (Dates will be provided by the publisher.)

Keywords OKMC, martensitic alloys, grain size, nanostructural evolution, neutron irradiation.

* Corresponding author: e-mail mchiapet@sckcen.be, Phone: +32 (0)14 333181

** e-mail Imalerba@sckcen.be, Phone: +32 (0)14 333090

$\mathrm{Fe}-\mathrm{Cr}-\mathrm{C}$ alloys with chromium concentrations in the range from $\sim 2 \mathrm{wt} \%$ to $12 \mathrm{wt} \%$ form ferritic-martensitic structures by rapid cooling from the austenite state already in the presence of relatively low carbon concentrations. In this process it is possible to obtain different ratios of ferrite and martensite, as well as formation of carbides, by varying the thermal treatment. The presence of ferrite or martensite might have an influence on the nanostructural evolution under irradiation of these alloys. Here, considering a tempered martensite reference alloy with $9 \% \mathrm{Cr}$, we make use of an already validated object kinetic Monte Carlo (OKMC) model in order to study the possible effect of the formation of martensite laths on the material nanostructural evolution under neutron irradiation, assuming that the relevant boundaries act as sinks for radiation defects. The results show that the reduction of the grain size (including in this definition the average size of prior austenite grains, packets, blocks and laths) does not play any relevant role until sizes of the order of $\sim 0.5 \mu \mathrm{m}$ are reached: for smaller grains the number of defects being absorbed by the boundaries becomes dominant. However, this threshold is lower than the experimentally observed martensite lath dimensions, thereby suggesting that what makes the difference in martensitic $\mathrm{Fe}-\mathrm{Cr}-\mathrm{C}$ alloys with respect to ferrite, concerning events and mechanisms taking place during irradiation, are not the lath boundaries as sinks. Differences between the nanostructural evolution under neutron irradiation in ferrite and martensite should therefore be ascribed to other factors.
1 Introduction High-Cr ferritic/martensitic steels are candidate structural materials in the breeding blanket of future fusion reactors [1], as well as for fuel cladding and other core components in GenIV reactors $[2,3]$. It is therefore important to develop computational models that are able to help understanding the mechanisms affecting their nanostructural evolution under irradiation. These steels present a structure that can be ferritic or martensitic in different proportion, depending on both composition and thermal treatment. Recent experiments reveal that ferrite and martensite experience different nanostructural evolution under irradiation, specifically swelling is more pronounced in ferrite than in martensite [4]. One possible reason for this behavior is that the lath structure of the martensite might be absorbing more defects than the large- grain structure of the ferrite. It is also typical of the tempered martensite microstructure that $\mathrm{C}$ atoms that did not form carbides segregate at the lath boundaries, leaving the matrix virtually free of $\mathrm{C}$ [5]: this effect has been already addressed in [6].

Martensite in steels is well-known to show a hierarchical microstructure consisting of packets containing blocks of laths. All the blocks of a packet are contained within prior austenitic grains. They present the same habit plane and consist of interleaved laths with a similar crystal orientation. Recently, it has also been recognized that, within a block, laths are reorganized in sub-blocks, each of which corresponds to a single variant characterized by the Kurdjumov-Sachs orientation relationship with the parent austenite $[7,8]$ that minimizes 
the energy by aligning the laths, so that they share a closepacked plane and close-packed direction. In the literature, martensite laths are reported not to exceed a few tens of $\mu \mathrm{m}$ in length and a few $\mu \mathrm{m}$ in width, while their thickness is $\sim 0.5 \mu \mathrm{m}$ [9], although the variability can be large. Subblock thicknesses are reported to measure, respectively, $\sim 0.5 \mu \mathrm{m}$ [9] and between $4 \mu \mathrm{m}$ [10] and $7 \mu \mathrm{m}$ [9], while the prior austenite grains are generally estimated to range between 10 and $60 \mu \mathrm{m}$ [11], depending on both thermal treatment and chemical composition of the material.

The complex morphology of the martensite affects for example the toughness and strength of steels, because the sub-block boundaries work as barriers to dislocation glidings, and eventually increase the strength of martensitic versus ferritic steels. Likewise, lath and subblock boundaries might also be expected to have an effect on the nanostructural evolution under irradiation of martensite alloys, because they may act as sinks for radiation defects.

In this work we explore the effect of the grain size on the nanostructural evolution under irradiation of martensitic steels, using an already developed OKMC model for neutron irradiated $\mathrm{Fe}-9 \% \mathrm{Cr}-\mathrm{C}$ alloys $[6,12]$. In our previous work $[6,12]$ it was shown that the free $\mathrm{C}$ content in $\mathrm{Fe}-\mathrm{Cr}-\mathrm{C}$ alloys, i.e. the amount of $\mathrm{C}$ in the matrix, which is higher in ferrite than in martensite, is able to partially counteract the beneficial effect of $\mathrm{Cr}$ in terms of suppression of void swelling. Here we investigate whether the smaller grain size of the martensitic structure has also an effect and, if so, whether this effect is more or less important than the change in free $\mathrm{C}$, in terms of impact on the nanostructure evolution of $\mathrm{Fe}-\mathrm{Cr}-\mathrm{C}$ alloys under neutron irradiation.

Specifically, we first consider a case of neutron irradiation at $290^{\circ} \mathrm{C}$ and at a dose-rate of $\sim 1 \times 10^{-7} \mathrm{dpa} / \mathrm{s}$, as dictated by the reference experiments $[13,14]$. The grain dimensions in the model were varied in a range going from the size of prior austenite grains to that of the sub-blocks, and down to sizes of the order of the martensite laths, or smaller. We then studied the influence of both irradiation temperature and dose-rate on the interactions between defect clusters and grain boundaries (GBs), for two grain sizes, namely 0.2 and $20 \mu \mathrm{m}$ : the first value has been chosen because it falls in a range where the effect of the grain size has been observed to be relevant, while $20 \mu \mathrm{m}$ is the average grain size for tempered martensite $\mathrm{Fe}-9 \% \mathrm{Cr}-\mathrm{C}$ [14].

The paper is organized as follows: the simulation method and the parameterization adopted are briefly presented in section 2, while in section 3 we show and compare the main results of our investigation. Finally, section 4 summarizes our conclusions.

2 Method and parameterization For all our simulations we used the object kinetic Monte Carlo (OKMC) code LAKIMOCA, thoroughly described in [15], while the approach we adopted is also explained in detail in $[6,16$, 17]. However, for convenience, we provide here a concise overview of the assumptions and the most relevant parameters that we have adopted. In our model we describe the nanostructure evolution of defects, namely vacancies (Va) and self-interstitial atoms (SIA) which may also form clusters, in materials subjected to irradiation, focusing on the properties of defects, treated as objects. Single carbon (C) atoms or carbon-vacancy $\left(\mathrm{C}_{2} \mathrm{Va}\right)$ complexes are also treated. Specifically, in our model $\mathrm{C}$ atoms and $\mathrm{C}_{2} \mathrm{Va}$ complexes act as immobile spherical traps for mobile defects (Va and SIA clusters) and are characterized, respectively, by a binding energy of 0.6 and $1.3 \mathrm{eV}$ towards clusters $>4$ SIA [6], while Va clusters bigger than size 6 are trapped with an energy of $0.35 \mathrm{eV}$ [6]. Every object inside the simulation volume is characterized by a set of coordinates and can thereby be tracked throughout the irradiation process [16].

It is important to note that $\mathrm{Cr}$ atoms are not introduced explicitly in the model, but their presence is reflected in the change of the mobility of SIA objects, i.e. applying a "grey alloy" approach [6] based on the works of Refs. [18, 19]. The properties of vacancy type defects, in contrast, are assumed not to be influenced by the presence of $\mathrm{Cr}$ : both experimental and theoretical studies show that $\mathrm{Cr}$ atoms in $\mathrm{Fe}$ interact only very weakly with vacancies, with hardly any influence on their stability and mobility [20, 21, 22].

SIA and $\mathrm{Va}$ objects have an associated reaction volume, which is generally spherical with the exception of large dislocation loops (>150 SIA) that are represented by toroids. Throughout the simulation, the defects and their clusters can undergo events such as migration, recombination, clustering or dissociation, which take place in the simulation volume (or box) according to pre-defined probabilities given in terms of Arrhenius frequencies for thermally activated processes:

$$
\Gamma_{i}=v_{i} \exp \left(\frac{-A_{i}}{k_{B} T}\right)
$$

Here $v_{i}$ is the attempt frequency (alias the prefactor) of the event $i ; A_{i}$ is the corresponding activation energy, which must embody both the thermodynamics and the kinetics of the system being studied; $k_{B}$ is the Boltzmann's constant and $T$ is the irradiation temperature expressed in $\mathrm{K}$. For every simulation step, among all the possible events, one is chosen, based on the corresponding probabilities and according to the stochastic Monte Carlo algorithm [23]. Time elapses according to the residence time algorithm [24]:

$$
\Delta t \propto \frac{1}{\sum_{1}^{N} \Gamma_{\mathrm{i}}}
$$


where the time increase is obtained as inverse of the sum of all the frequencies $\Gamma_{i}$ associated with each of the $N$ possible independent events.

Our model simulates the damage production from the impinging neutron flux with a random introduction in the simulation system of $\mathrm{Va}$ and SIA objects of different sizes, representing debris of displacement cascades, as well as of residual Frenkel pairs [15]. The displacement cascades used were simulated using molecular dynamics (MD) [2527] and range over different energies ( $5 \mathrm{keV}, 10 \mathrm{keV}, 20$ $\mathrm{keV}, \ldots, 100 \mathrm{keV})$. The number of introduced defects per unit time and volume directly corresponds to a well defined dpa rate, while the accumulated dpa is calculated using the NRT formula [23]. At every simulation of neutron irradiation a residual Frenkel pair or a displacement cascade of a certain energy have the same probability to be picked.

Grain boundaries act as a spherical surface sinks for defect clusters of all sizes. In the model the absorption of $\mathrm{Va}$ and SIA defects is taken into account by applying the algorithm described in [28]: since the moment it appears in the box each object has two sets of coordinates, one, subjected to periodic boundary conditions, that expresses its position in the simulation box, and a second one, not subjected to periodicity, that expresses its distance from the centre of a supposedly spherical grain. Defect objects are absorbed by grain boundaries as soon as one of the following situations occurs: i.) the defect object reaches the grain boundary, or ii.) the distance travelled by the defect object equals the grain radius, irrespective of its position inside the box. In this work, the grain size was varied between $250 \mu \mathrm{m}$ (size adopted in [16, 17] and typical of ferritic $\mathrm{Fe}-\mathrm{C}$ ) and $0.1 \mu \mathrm{m}$, which is about five times lower than the typically smallest possible size of martensite laths in one direction of space. Thus, in our OKMC model the concept of grain size is translated into a diameter, representing the average effective size of the material elements (e.g. martensite laths) that we want to investigate.

A second kind of sink in irradiated material are dislocations, which are reproduced here by spherical sinks randomly distributed in the simulation volume: their number and size are chosen in such a way that the sink strength associated with them equals the corresponding material dislocation density [6, 29]. However, we only allow defect clusters smaller than the core of the dislocations, i.e. size $1-4$, to be absorbed because bigger SIA clusters are often observed by transmission electron microscopy to decorate dislocations in the alloys of interest $[5,14,30]$. The dislocation density of the reference Fe$9 \% \mathrm{Cr}-\mathrm{C}$ model alloys was reported to be $6.3 \times 10^{13} \mathrm{~m}^{-2}[5]$.

The $\mathrm{C}$ concentration in the matrix, that determines the concentration of traps for point defect clusters, unless otherwise stated, is assumed to be 20 appm, according to $[6,31]$.

All other parameters used here are exactly the same as reported in [6]. All simulations were performed in a non- cubic simulation box of size $600 \times 750 \times 1000 a_{0}{ }^{3}\left(a_{0}=\right.$ $2.87 \times 10^{-10} \mathrm{~m}$ is the lattice parameter of $\left.\alpha-\mathrm{Fe}\right)$ in order to avoid potential anomalies from $1 \mathrm{D}$-migrating defects entering a migration trajectory loop, as discussed in [32], due to the periodic boundary conditions which were applied in all three directions.

3 Results Figure 1 shows the number density of both $\mathrm{Va}$ and SIA objects present in the simulation system at $10^{-3}$ $\mathrm{dpa}$, as a function of the grain size. The ordinate axis is in logaritmic scale and all values refer to a dose-rate of $\sim 10^{-7}$ $\mathrm{dpa} / \mathrm{s}$ and to an irradiation temperature of $290^{\circ} \mathrm{C}$. It can be clearly seen that, below $\sim 0.5 \mu \mathrm{m}$, there is an important drop in the total amount of surviving defects, as a consequence of the fact that most SIA and $\mathrm{Va}$, both single defects and defect clusters, are absorbed by the GBs. Above this threshold, the number of SIA and Va objects that interact with GBs has been verified to gradually decrease with the increase of the grain size, in agreement with [32], while the nanostructural evolution under neutron irradiation of $\mathrm{Fe}-9 \% \mathrm{Cr}-\mathrm{C}$ is not altered any more by the choice of the grain size: both SIA and Va object number densities and mean sizes remain constant for values bigger than $\sim 0.5-1 \mu \mathrm{m}$ and similar irradiation conditions.

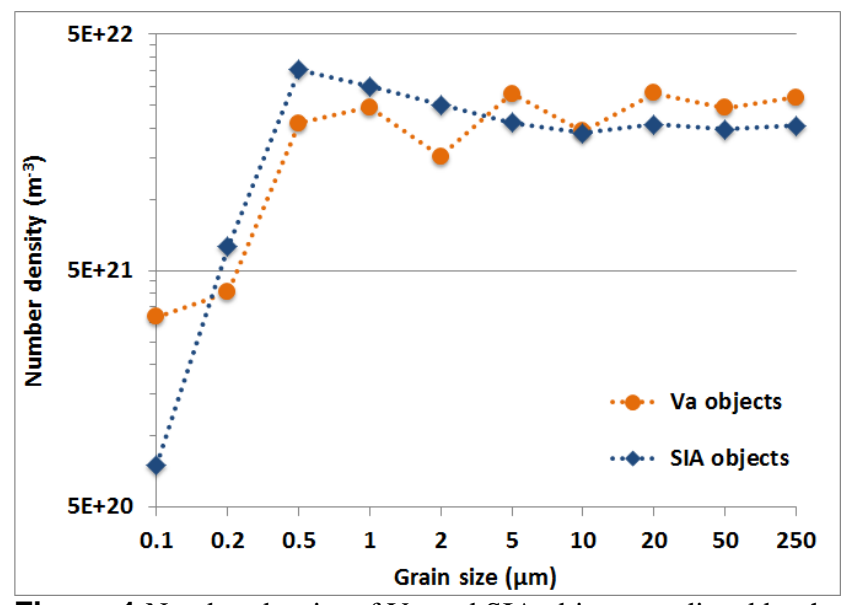

Figure 1 Number density of Va and SIA objects predicted by the OKMC model to be present in the simulation system at $10^{-3} \mathrm{dpa}$, as a function of grain size.

Figure 2 shows two electron back-scatter diffraction (EBSD) images for the same analyzed section of the modeled Fe-9\%Cr-C alloy. They show the unique grain color maps for the martensite laths (a) and for the martensite blocks (b): the lath thickness and average size of the martensitic blocks were found to be, respectively, 2.6 and $4.4 \mu \mathrm{m}$. Since the experimental value for the lath thickness is several times larger than the threshold value of $\sim 0.5-1 \mu \mathrm{m}$ suggested by our OKMC model, we can conservatively conclude that the presence of martensite laths should not be considered as a major factor influencing the evolution of the system of interest under irradiation. From the same ESBD data analysis it was also 
possible to establish that most misorientations between martensite blocks are $>30^{\circ}$, with a peak about $60^{\circ}$ (representing stable martensitic boundaries formed by the orientation relationship with prior austenite grains). However, in this range of grain misorientations the absorption efficiency of radiation-induced defects at the grain boundary is not expected to vary significantly. Finally, between laths no major preferences for misorientation (of low angle type, with maximum values around $15^{\circ}$ ) were observed, with corresponding negligible expected influence on defect $a b$ sorption efficiency.
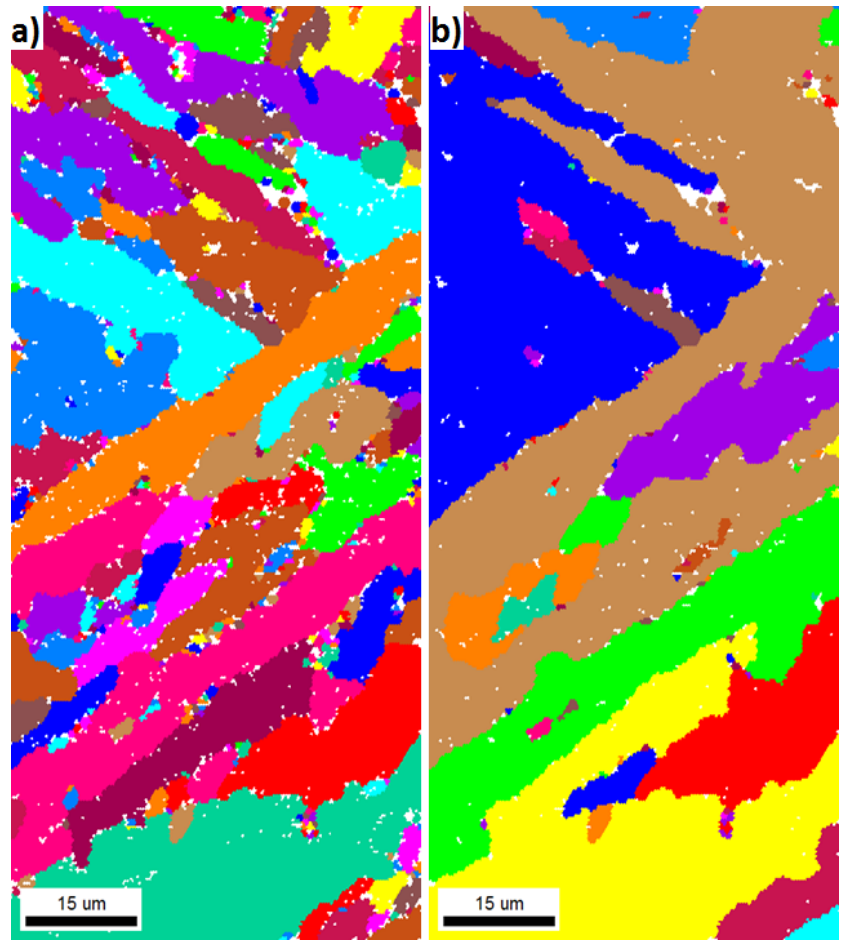

Figure 2 EBSD images for the same analyzed area of the modeled Fe-9\% Cr-C alloy. The unique grain color maps for the martensite laths (a) and for the martensite blocks (b) are reported.

Since in Ref. [6] the actual C concentration in the matrix has been identified as the main responsible in tempered martensite $\mathrm{Fe}-\mathrm{Cr}-\mathrm{C}$ alloys for partially counteracting the beneficial effect of $\mathrm{Cr}$ on void swelling, the vacancy cluster size distribution in neutron irradiated $\mathrm{Fe}-9 \% \mathrm{Cr}-\mathrm{C}$ at $0.001 \mathrm{dpa}$ has been here analyzed for three different $\mathrm{C}$ concentrations in the matrix, namely 2, 20 and $134 \mathrm{appm}$. The last two values correspond, respectively, to the experimental $\mathrm{C}$ concentration in the neutron-irradiated $\mathrm{Fe}-9 \% \mathrm{Cr}-\mathrm{C}$ alloy and to the free $\mathrm{C}$ concentration characteristic of ferrite Fe-C [16]. The main objective was to study whether void swelling is mostly influenced by the $\mathrm{C}$ content in the matrix rather than from the choice of the grain dimension. In order to do this, two grain sizes $(0.2$ and $20 \mu \mathrm{m}$ ) were investigated.

Figure 3 shows that, regardless of the dimension of the grain, the lower $\mathrm{C}$ concentration never allows the formation of big vacancy clusters. For the other C concentrations, instead, the formation of bigger vacancy clusters was observed, especially in the case of the higher $\mathrm{C}$ content. It is also relevant to notice that $\mathrm{C}$ is seen to play a role on vacancy clustering only for grain sizes larger than $\sim 0.5 \mu \mathrm{m}$ : in this case for relatively high $\mathrm{C}$ concentrations the effect of $\mathrm{Cr}$ on SIA cluster mobility is not enough alone to completely suppress the formation of bigger vacancy clusters. At very low $\mathrm{C}$ concentrations, in contrast, the reduced presence of traps for defect objects makes the latter more likely to reach sinks and be absorbed at GBs, thereby preventing vacancies from clustering.

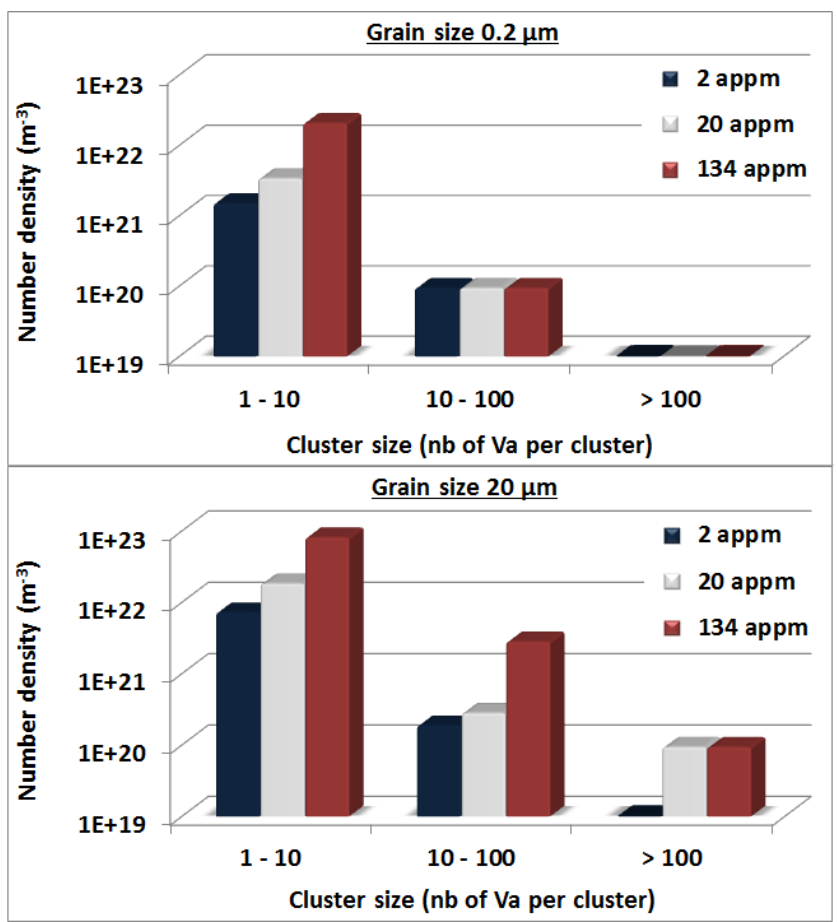

Figure 3 Size distribution, expressed in number density, of the vacancy cluster population for three different $\mathrm{C}$ concentrations: results for a grain size of $0.2 \mu \mathrm{m}$ (above) and $20 \mu \mathrm{m}$ (below) are reported. All model predictions are given for $10^{-3} \mathrm{dpa}$.

In Figure 4 the effect of the irradiation temperature on the number of absorptions of defect objects at GBs is shown for two grain sizes, $0.2 \mu \mathrm{m}$ (above) and $20 \mu \mathrm{m}$ (below). Three different irradiation temperatures (250, 290 or $330^{\circ} \mathrm{C}$ ) were investigated at a constant dose-rate of $\sim 10^{-7} \mathrm{dpa} / \mathrm{s}$. Each histogram bar represents a different irradiation temperature and is composed by the relative contributions to the total number of absorptions at GBs (in percentage) of the two classes of defect populations.

The superimposed orange lines represent the total fraction of absorbed defects: the number of absorptions at GBs increases with the irradiation temperature in the case of the larger grain size, while for a grain dimension of $0.2 \mu \mathrm{m}$ any effect of the irradiation temperature on the nanostructural evolution of the material appears to be 
inhibited. The first result is intuitive because, at higher temperature, defect clusters are more mobile and thus also more likely to diffuse through distances comparable with that of the grain size. The defect behavior at the GBs in the case of the smaller grain size, on the other hand, is in agreement with that shown in Figure 1: below grain sizes of $\sim 0.5-1 \mu \mathrm{m}$ the role of GBs as sinks for defects becomes dominant.

Solute atoms are transported by point defects, thus radiation induced segregation [33] can be used as a verification of the temperature above which the absorption of defects at GBs becomes important. As a matter of fact, the element concentrations at grain boundaries changes under irradiation, either opposite to the direction of the vacancy flux (inverse Kirkendall effect), i.e. away from sinks, or in the same direction, if an attraction exists between vacancies and solutes (or by interstitial mechanism), thereby influencing some material properties, such as ductility, strength or corrosion resistance. The results given in Figure 4 for the $20 \mu \mathrm{m}$ grain size suggest that only at $330^{\circ} \mathrm{C}$ more than $50 \%$ of the absorbed defects disappear at grain boundaries, consistently with Ref. [34], where radiation-induced $\mathrm{Cr}$ segregation at GBs was reported to sharply increase with temperature, at $\sim 350^{\circ} \mathrm{C}$ : although this result was obtained for austenitic steels and not for tempered martensite, it can nonetheless be used as indicative experimental reference for our study. Moreover, in Ref. [12] a significant number density reduction for both defect populations was also observed above $\sim 290^{\circ} \mathrm{C}$ as a consequence of the enhanced defect mobilities with temperature, which resulted in an increase of defect absorptions at sinks.

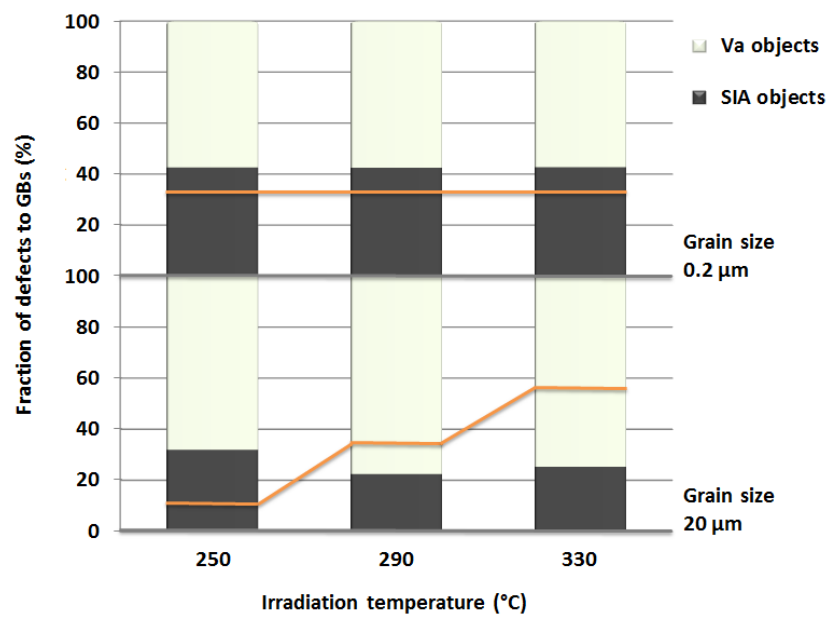

Figure 4 Relative contribution to the total number of absorptions at GBs of V and SIA objects at $5 \times 10^{-4}$ dpa and $10^{-7} \mathrm{dpa} / \mathrm{s}$, for different irradiation temperatures. OKMC results for two grain sizes are reported: $0.2 \mu \mathrm{m}$ (above) and $20 \mu \mathrm{m}$ (below). The superimposed orange lines represent the total fraction of absorbed defects at GBs, separately for the two analyzed grain sizes.

In Figure 5 shows a similar analysis conducted for three different dose-rates $\left(1 \times 10^{-9}, 1 \times 10^{-7}\right.$ and $\left.1 \times 10^{-5} \mathrm{dpa} / \mathrm{s}\right)$, at a constant irradiation temperature of $290^{\circ} \mathrm{C}$. The lowest dose-rate approaches the value seen by the corecomponents of a reactor, while the highest value may correspond to ion irradiation. Again, the effect of the dose-rate on the number of absorptions of defect clusters at GBs is shown for two grain sizes of reference, $0.2 \mu \mathrm{m}$ (above) and $20 \mu \mathrm{m}$ (below). Each histogram bar represents a different dose-rate and is composed by the relative contributions to the total number of absorptions at GBs (in percentage) of the two classes of defect populations. The superimposed red lines represent the total fraction of absorbed defects: for the larger grain size the number of absorptions at GBs is seen to significantly decrease when higher dose-rates are applied. This result can be explained in terms of a twofold effect: on the one side, at higher dose-rates more defects per unit time form in the bulk and they have no time to diffuse to the GBs before the reference dose (i.e. $5 \times 10^{-4} \mathrm{dpa}$ ) is reached; on the other, the formation of bigger (and thus slower) vacancy clusters is observed as a direct consequence of the shorter lapse of time between cascades, which leads to enhanced clustering (Figure 6). For the grain dimension of $0.2 \mu \mathrm{m}$, instead, almost no effect is observed with the dose-rate, similarly to what already discussed in Figure 4, i.e. as a consequence of the dominance of grain boundaries as sinks, irrespective of other irradiation conditions.

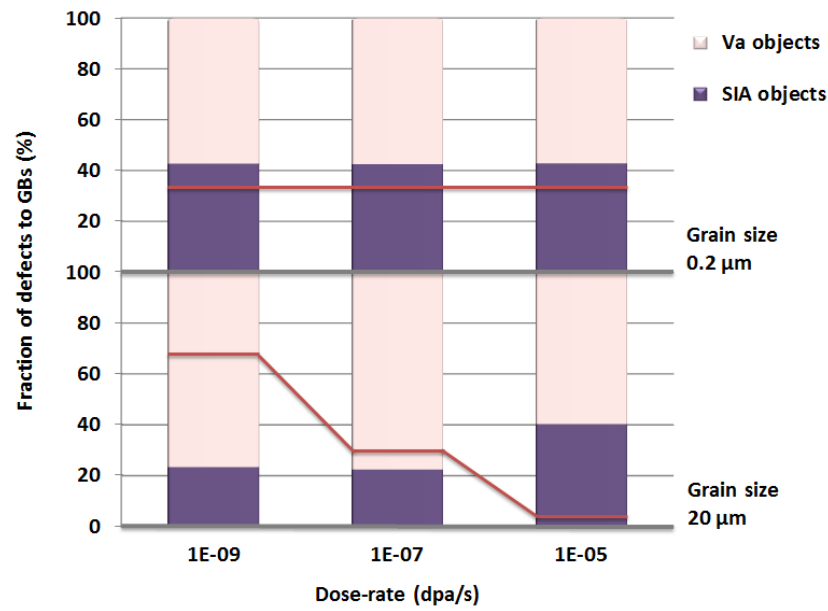

Figure 5 Relative contribution to the total number of absorptions at GBs of V and SIA objects at $5 \times 10^{-4} \mathrm{dpa}$ and $290^{\circ} \mathrm{C}$, for different dose-rates. OKMC results for two grain sizes are reported: $0.2 \mu \mathrm{m}$ (above) and $20 \mu \mathrm{m}$ (below). The superimposed red lines represent the total fraction of absorbed defects at GBs, separately for two analyzed grain sizes.

In Figure 6 the vacancy cluster number density at the three dose-rates analyzed is reported for both grain sizes of 0.2 and $20 \mu \mathrm{m}$. It is possible to notice that with a larger grain size the vacancy cluster dimensions tend to increase at higher dose-rates, while the defect number densities are also higher. This result is in agreement with Ref. [12], where it is clearly shown that an increase in dose-rate leads 
to higher densities in $\mathrm{Fe}-\mathrm{Cr}-\mathrm{C}$ alloys. However, this effect can be compensated by smaller grain sizes, which are optimum competitors to void nuclei as vacancy absorbers, thereby probably hindering the appearance of radiationinduced swelling in martensitic alloys.

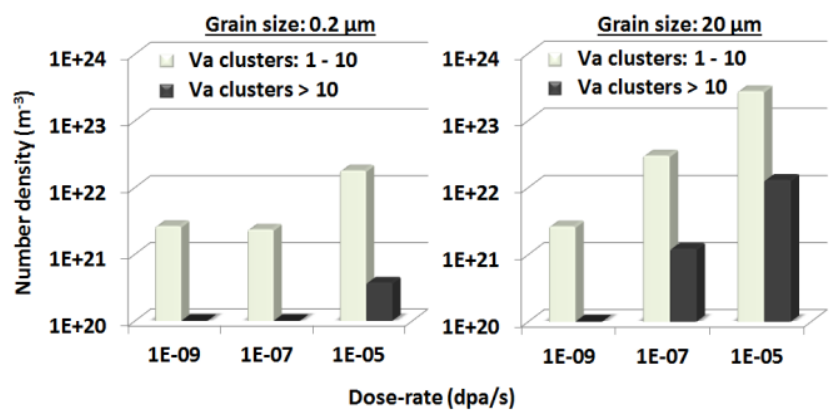

Figure 6 Size distribution of the vacancy cluster population for three different dose-rates and two grain sizes: $0.2 \mu \mathrm{m}$ (left) and $20 \mu \mathrm{m}$ (right). All results are given at $5 \times 10^{-4} \mathrm{dpa}$.

One more remark concerns the proportion between $\mathrm{Va}$ and SIA objects that interact with GBs when a grain size of $20 \mu \mathrm{m}$ is assumed. Figure 4 shows that the amount of $\mathrm{Va}$ objects being absorbed at GBs is always bigger by a factor 2-3 than that of SIA objects. The same consideration can be extended to the two lower dose-rates shown in Figure 5, while for the neutron flux of $1 \times 10^{-5} \mathrm{dpa} / \mathrm{s}$ the number of SIA and Va objects reaching the GBs was found to be almost the same, meaning that, despite their different diffusivity, there was no difference in flux towards GBs for the two radiation-induced defect populations. This result can be explained in terms of ratio between the time that elapses between cascades and the average time required for defects to diffuse until the GBs. In order to clarify this statement, in Figure 7 we report the average distance that each object up to size 10 , either SIA or $\mathrm{Va}$, covers in 50 seconds, which correspond to the time needed to reach $5 \times 10^{-4}$ dpa under a neutron flux of $10^{-5} \mathrm{dpa} / \mathrm{s}$ at $290^{\circ} \mathrm{C}$, expressed as:

$$
d=\lambda \sqrt{N}
$$

Where: $\lambda=a_{0} \frac{\sqrt{3}}{2}$ and the number of jumps is obtained as $N=\Gamma \Delta t$, with $\Gamma$ given by Eq. (1).

Clearly, migration is not the only event allowed for defect objects in an OKMC simulation, so the presence of traps will significantly reduce the diffusivity of defect clusters; furthermore, single $\mathrm{Va}$ are easily emitted from bigger clusters at $\sim 300^{\circ} \mathrm{C}$, thereby increasing the amount of small and more mobile $\mathrm{Va}$ defects that are present in the simulated system. Va point defects and small Va clusters are thus more likely than trapped SIA clusters to reach grain boundaries and be absorbed, even if, a priori, 1D migrating defects are expected to reach the GB more efficiently: bigger cluster sizes and interactions with traps significantly reduce their mobility. Moreover, not all SIA and Va objects are introduced in the system since the very beginning of the simulation. Thus, the distances reported in Figure 7 can only be regarded as an upper limit. However, what is important to notice is that both SIA and Va type objects have time to cover a distance of $0.1 \mu \mathrm{m}$ (i.e. radius corresponding to the smaller grain size), so they can be both absorbed at GBs.

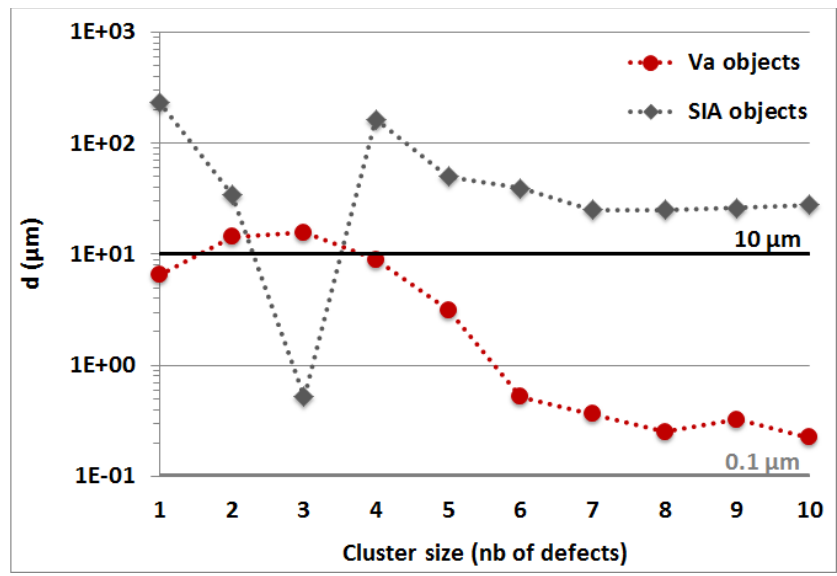

Figure 7 Average distance that SIA and V defect objects can travel in $50 \mathrm{~s}$ at $290^{\circ} \mathrm{C}$, as a function of defect size. The radii of the grain sizes of interest have also been indicated.

Finally, the role of martensite lath boundaries as major point defect sinks during neutron irradiation assumes even more importance if we consider that irradiation induced segregation at GBs is attributed to a preferential coupling of point defects with solute atoms (SIA with $\mathrm{Cr}, \mathrm{Mn}$ and $\mathrm{P}$, all other solutes with $\mathrm{Va}$ [33]). The diffusion of solutes to $\mathrm{GBs}$ is thus driven by differences in single defect fluxes within the matrix [34] and solute segregation may thus be suppressed, or at least be hindered, in the case of higher fluxes or lower irradiation temperatures.

The current OKMC model for martensite $\mathrm{Fe}-\mathrm{Cr}-\mathrm{C}$ steels adopts a "grey alloy" approach. Therefore, solute atom transport is not simulated and so no information can be deduced on the evolution under irradiation of the chemical composition at grain boundaries. Despite this the results reported here show that the reduction of the grain size, within sizes typical of martensite laths, does not play a major role on the nanostructural evolution under neutron irradiation in martensitic alloys, thereby suggesting that the different response to neutron irradiation of martensite and ferrite alloys must be ascribed to other factors, such as chemical composition or carbon concentration in the matrix.

4 Conclusions This work shows that, within sizes typical of martensite laths, the choice of the grain size does not have large influence on the nanostructural evolution under neutron irradiation of $\mathrm{Fe}-\mathrm{Cr}-\mathrm{C}$ alloys. On the basis of our OKMC model, it was possible to conclude that the 
role of GBs as sinks for defect objects becomes dominant only below grain sizes of the order of $\sim 0.5-1 \mu \mathrm{m}$. The approach that we implemented did not take into account the effect of misorientations between neighboring grains. Nonetheless, from ESBD data analysis on a sample of the modeled $\mathrm{Fe}-9 \% \mathrm{Cr}-\mathrm{C}$ alloy it was observed that most misorientations between the martensite blocks are $>30^{\circ}$, with a peak about $60^{\circ}$ : in this range of grain misorientations the absorption efficiency of radiation-induced defects at the grain boundary is expected to be negligible. Moreover, in our model we assume spherical grains while laths are elongated, so our results can be considered rather conservative. This allows us to state that, since $\sim 0.5-1 \mu \mathrm{m}$ also coincides with the lower bound size for martensite laths as reported in the literature and it is at the same time much smaller that the lath thickness suggested by EBSD data analysis on samples of the model alloy used here as reference, in martensite $\mathrm{Fe}-\mathrm{Cr}-\mathrm{C}$ alloys the material nanostructural behavior is not significantly altered by the presence of the martensite laths.

The total number of $\mathrm{Va}$ and SIA objects absorbed at GBs was also verified to increase with irradiation temperature, in agreement with analogous experimental observations [35], as well as to be significantly reduced when the dose-rate approaches $\sim 10^{-5} \mathrm{dpa} / \mathrm{s}$. This result is of particular interest because martensite $\mathrm{Fe}-\mathrm{Cr}-\mathrm{C}$ steels are, between others, candidate structural materials for fuel cladding and other core components in GenIV reactors [2, 3] where the irradiation fluxes are expected to be higher than in commercial light water reactors.

Acknowledgements The research leading to these results was also partly funded by the Euratom's Seventh Framework Programme FP7/2007-2013 under grant agreement No. 604862 (MatISSE project) and contributes to the EERA (European Energy Research Alliance) Joint Programme on Nuclear Materials (JPNM). The views and opinions expressed herein do not necessarily reflect those of the European Commission.

\section{References}

[1] H. Tanigawa et al., J. Nucl. Mater. 417 (2011) 9-15.

[2] T.R. Allen et al., JOM 60 (2008) 15-23.

[3] Yeong-il Kim et al., Sci. Technol. Nucl. Ins. 2013 (2013) 290-362.

[4] V. Bryk at al., "Ion issues on irradiation behaviour of structural materials at high doses and gas concentrations", Proceedings $11^{\text {th }}$ International Topical Meeting on Nuclear Applications of Accelerators (AccApp Conference, 2013), 5-8 August, 2013, Bruges, Belgium.

[5] M. Konstantinovic et al., these proceedings.

[6] M. Chiapetto, L. Malerba, C.S. Becquart, J. Nucl. Mater. 465 (2015) 326-336.

[7] S. Morito, H. Tanaka, R. Konishi, T. Furuhara and T. Maki, Acta Mater. 51 (2003) 1789-1799.

[8] S. Morito, X. Huang, T. Furuhara, T. Maki and N. Hansen, Acta Mater. 54 (2006) 5323-5331.
[9] S. Morito, Y. Adachi, T. Ohba, Mater. Trans., Vol. 50, No. 8 (2009) pp. 1919-1923.

[10] T. Karthikeyan, M.K. Dash, S. Saroja, M. Vijayalakshmi, Micron 68 (2015) 77-90.

[11] H.S. Yang, H.K.D.H. Bhadeshia, Scr. Mater. 60 (2009) 493-495.

[12] M. Chiapetto, C.S. Becquart, L. Malerba, Simulation of nanostructural evolution under irradiation in $\mathrm{Fe}-9 \% \mathrm{Cr}-\mathrm{C}$ alloys: an object kinetic Monte Carlo study of the effect of temperature and dose-rate, Nucl. Mater. Energy (2016), Article in Press.

[13] M. Matijasevic, A. Almazouzi, J. Nucl. Mater. 377 (2008) 147-154.

[14] M. Hernández-Mayoral, C. Heintze, E. Oñorbe, J. Nucl. Mater. 474 (2016) 88-98.

[15] C. Domain, C. Becquart, L. Malerba, J. Nucl. Mater. 335 (2004) 121-145.

[16] V. Jansson, M. Chiapetto, L. Malerba, J. Nucl. Mater. 442 (2013) 341-349.

[17] V. Jansson, L. Malerba, J. Nucl. Mater. 443 (2013) 274285.

[18] D. Terentyev, L. Malerba, A.V. Barashev, Philos. Mag. Lett. 85 (2005) 587-594.

[19] D. Terentyev, M. Klimenkov, L. Malerba, J. Nucl. Mater. 393 (2009) 30-35.

[20] L. Malerba, A. Caro, J. Wallenius, J. Nucl. Mater. 382 (2008) 112-125.

[21] P. Olsson, T.P.C. Klaver, C. Domain, Phys. Rev. B 81 (2010) 054102.

[22] E. del Rio, J.M. Sampedro, H. Dogo, M.J. Caturla, M. Caro, A. Caro, J.M. Perlado, J. Nucl. Mater. 408 (2011) 18-24.

[23] A.B. Bortz, M.H. Kalos, J.L. Lebowitz, J. Comput. Phys. 17, (1975) 10-18.

[24] W. Young, E. Elcock, Proc. of the Physical Society 89 (1966) 735-746.

[25] R. Stoller, J. Nucl. Mater. 233 (1996) 999-1003.

[26] R. Stoller, G. Odette, B.Wirth, J. Nucl. Mater. 251 (1997) 49-60.

[27] R. Stoller, A. Calder, J. Nucl. Mater. 283 (2000) 746-752.

[28] C. Domain, C. Becquart, L. Malerba, in: N. Ghoniem (Ed.), Proc. of Second International Conference on Multiscale Materials Modeling: October 11-15, 2004, Los Angeles, California, Mechanical and Aerospace Engineering Department, University of Calif., 2004.

[29] F. Nichols, J. Nucl. Mater. 75 (1978) 32-41.

[30] M. Hernández-Mayoral, D. Gómez-Briceño, J. Nucl. Mater. 399 (2010) 146-153.

[31] E.E. Zhurkin, D. Terentyev, M. Hou, L. Malerba, G. Bonny, J. Nucl. Mater. 417 (2011) 1082-1085.

[32] L. Malerba, C.S. Becquart, C. Domain, J. Nucl. Mater. 360 (2007) 159-169.

[33] L. Messina, PhD Thesis, KTH Royal Institute of Technology, Stockholm 2015.

[34] P.E.J. Flewitt, R.K. Wild, Grain Boundaries: Their Microstructure and Chemistry, John Wiley \& Sons Ltd, USA, 2001.

[35] S.M. Bruemmer, L.A. Charlot, J.S. Vetrano, E.P. Simonen, MRS Proceedings, Vol. 373 (1994) 119-131. 